\begin{tabular}{|c|c|c|c|}
\hline$C a c 0 D$ & \multicolumn{2}{|c|}{ Case Rep Gastroenterol 2015;9:261-265 } & \multirow[b]{2}{*}{$\begin{array}{l}\text { Karger } \\
\text { Open access }\end{array}$} \\
\hline nterology & $\begin{array}{l}\text { DOI: } 10.1159 / 000437321 \\
\text { Publisned onlIne: July 24, } 2015\end{array}$ & $\begin{array}{l}\text { (C) } 2015 \text { S. Karger AG, Basel } \\
\text { 1662-0631/15/0092-0261 } \$ 39.50 / 0 \\
\text { www.karger.com/crg }\end{array}$ & \\
\hline & $\begin{array}{l}\text { This is an Open Access article lice } \\
\text { NonCommercial } 3.0 \text { Unported lice } \\
\text { the online version of the article on }\end{array}$ & $\begin{array}{l}\text { ns of the Creative Commons Attributio } \\
\text { Nw.karger.com/OA-license), applicable } \\
\text { nitted for non-commercial purposes onl }\end{array}$ & \\
\hline
\end{tabular}

\title{
Abnormal Liver Function Tests in an Anorexia Nervosa Patient and an Atypical Manifestation of Refeeding Syndrome
}

\author{
Vamshidhar R. Vootla Myrta Daniel \\ Division of Gastroenterology, Bronx Lebanon Hospital Center, Bronx, N.Y., USA
}

\section{Key Words}

Refeeding syndrome $\cdot$ Anorexia nervosa $\cdot$ Abnormal liver function tests

\begin{abstract}
Refeeding syndrome is defined as electrolyte and fluid abnormalities that occur in significantly malnourished patients when they are refed orally, enterally, or parenterally. The principal manifestations include hypophosphatemia, hypokalemia, vitamin deficiencies, volume overload and edema. This can affect multiple organ systems, such as the cardiovascular, pulmonary, or neurological systems, secondary to the above-mentioned abnormalities. Rarely, patients may develop gastrointestinal symptoms and show abnormal liver function test results. We report the case of a 52-year-old woman with anorexia nervosa who developed refeeding syndrome and simultaneous elevations of liver function test results, which normalized upon the resolution of the refeeding syndrome.

(C) 2015 S. Karger AG, Basel
\end{abstract}

\section{Case Report}

A 52-year-old Caucasian woman was admitted to our hospital from the nursing home due to refusal of percutaneous endoscopic gastrostomy tube feeding and altered mental status, which was attributed to hypoglycemia and urinary tract infection. Her medical history was significant for long-standing severe anorexia nervosa, depression and recent percutaneous endoscopic gastrostomy tube placement for nutritional support at another hospital. She was allergic to ciprofloxacin and penicillin and her nursing home medications included multivitamin, megestrol, ferrous sulfate, calcium carbonate, ranitidine, thiamine, folic acid, and olanzapine. 
Vootla and Daniel: Abnormal Liver Function Tests in an Anorexia Nervosa Patient and an Atypical Manifestation of Refeeding Syndrome

Upon admission, her weight was $21 \mathrm{~kg}$ and her BMI was 7.9, which amounted to approximately $40 \%$ of her ideal body weight. The vital signs were normal. The patient was bed bound, alert and well oriented. The physical exam revealed dry skin, excoriations all over the body, brittle nails, pallor and profound emaciation with bitemporal wasting. Her abdomen was scaphoid without organomegaly, and she had a percutaneous endoscopic gastrostomy tube with granulation tissue surrounding the stoma. There were no stigmata of chronic liver disease. The remainder of her physical examination was unremarkable.

Laboratory investigations revealed hemoglobin of $8.4 \mathrm{~g} / \mathrm{dl}$, white cell count of $3.5 \mathrm{k} / \mu \mathrm{l}$, platelet count of $230 \mathrm{k} / \mu \mathrm{l}$, prothrombin time of $12 \mathrm{~s}$ and activated partial thromboplastin time of $29 \mathrm{~s}$, normal serum electrolytes except for a blood sugar level of 56. Her liver function tests showed serum alanine aminotransferase of 32 units/l, serum aspartate aminotransferase of 32 units/l and serum total bilirubin of $0.6 \mathrm{mg} / \mathrm{dl}$.

She continued to refuse oral and tube feeding and she had intermittent episodes of hypoglycemia. She was evaluated by psychiatrists and was deemed to lack decisional capacity. It was recommended that percutaneous endoscopic gastrostomy tube feeding be imposed for nutritional support. After consultation with the nutritional team, tube feeding was begun at $400 \mathrm{kcal} /$ day and advanced gradually over the next 5 days to $900 \mathrm{kcal} /$ day.

Five days after the initiation of feeding, she developed tachycardia and lab work revealed electrolyte abnormalities such as hypophosphatemia (phosphorus $0.8 \mathrm{mg} / \mathrm{dl}$ ) and hypokalemia (potassium $2.9 \mathrm{mEq} / \mathrm{l}$ ) (fig. 1). An electrocardiogram was done, which showed sinus tachycardia with some premature ventricular complexes and prolonged QT interval (QTc 472). She was then evaluated by cardiologists and nutritional teams. A diagnosis of refeeding syndrome was made, and the patient was transferred to the telemetry unit for further management. Further laboratory tests revealed elevated transaminases (alanine aminotransferase 193 units/l, aspartate aminotransferase 173 units/l), alkaline phosphatase (392 IU/l) and bilirubin (1.4 mg/dl), which were normal upon admission (fig. 2). A consultation with a gastroenterologist was called. Viral hepatitis was excluded by serological tests and autoimmune workup, including anti-smooth muscle antibody, anti-liver/kidney microsomal antibody, antinuclear antibody and antimitochondrial antibody, was negative. Serum ceruloplasmin level was normal. Other causes of hepatitis such as hepatotoxic drugs were excluded. The liver and pancreas appeared normal on a computed tomogram. An abdominal ultrasound revealed normal echotexture of the liver without intra- or extrahepatic biliary dilatation and normal Doppler evaluation of the hepatic and portal vein blood flow.

Infusions of potassium phosphate and magnesium sulfate were administered in addition to oral potassium phosphate supplements. Intravenous thiamine was given. Her enteral intake was reduced and daily electrolyte levels were obtained along with regular monitoring of the liver function tests. The liver enzymes started improving after reduction of the tube feeding rate. Electrolytes also normalized over the next few days and the patient was eventually discharged.

\section{Discussion}

Anorexia nervosa is characterized by severe protein energy malnutrition, abnormally low body weight and is often accompanied by additional psychopathological disorders [1]. Several studies and case reports have highlighted increases in serum liver enzymes in patients with anorexia nervosa or extreme malnutrition [2]. The majority of them have reported abnormal liver function test results occurring prior to the initiation of any nutritional supplementation and improvement of enzymes upon feeding. Hepatocellular injury in such 
Vootla and Daniel: Abnormal Liver Function Tests in an Anorexia Nervosa Patient and an Atypical Manifestation of Refeeding Syndrome

patients has sometimes been called starvation hepatitis and is attributed to several mechanisms triggered by malnutrition including apoptosis/autophagy, hypoperfusion of the liver, hypoxia, oxidative stress, and iron deposition $[3,4]$.

Rarely, there have been reports of anorexic patients with rapid and profound elevations in liver enzymes, specifically transaminases upon initial refeeding associated with refeeding syndrome [5, 6]. A Medline search using the key words 'anorexia nervosa', 'refeeding syndrome' and 'abnormal liver function tests' revealed two case reports from 2000 to 2014 $[7,8]$.

Refeeding syndrome is a potentially lethal condition, which is broadly defined as severe electrolyte and fluid shifts associated with metabolic abnormalities in malnourished patients undergoing refeeding either orally, enterally, or parenterally. Rarely, asymptomatic mild elevations of liver enzymes may be seen during refeeding. A hepatic manifestation as part of metabolic abnormalities can occur during the initial few weeks of refeeding. They are more common in those patients being refed enterally or with total parenteral nutrition. Usually, elevations in aspartate aminotransferase and alanine aminotransferase are noted and may sometimes be followed by a rise in alkaline phosphatase and bilirubin. Usually, these abnormalities revert to normal levels upon reduction of the rate of feeding.

The pathophysiology of this has not been clarified, but a few hypotheses have been postulated [9] and out of them refeeding steatosis/steatohepatitis has gained the most attention. It is attributed to fat accumulation in the hepatocytes secondary to excessive dextrose and carbohydrate supplementation in a severely malnourished patient during the refeeding phase [10-12].

We conclude that the development of refeeding syndrome may manifest as abnormal liver function along with electrolyte abnormalities. We recommend close monitoring of liver function tests in patients who are being refed after a long period of starvation as abnormal liver chemistry values may be a harbinger of the refeeding syndrome. We also emphasize the fact that one should 'start low and go slow' in the management of refeeding in anorexia nervosa patients.

\section{Disclosure Statement}

On behalf of all authors, the corresponding author states that there is no conflict of interest.

\section{References}

1 Modlin IM, Lye KD, Kidd M: A 5-decade analysis of 13,715 carcinoid tumors. Cancer 2003;97:934-959.

2 Mickley D, Greenfeld D, Quinlan DM, Roloff P, Zwas F: Abnormal liver enzymes in outpatients with eating disorders. Int J Eat Disord 1996;20:325-329.

-3 Tsukamoto M, Tanaka A, Arai M, Ishii N, Ohta D, Horiki N, Fujita Y: Hepatocellular injuries observed in patients with an eating disorder prior to nutritional treatment. Intern Med 2008;47:1447-1450.

-4 Rautou PE, Cazals-Hatem D, Moreau R, Francoz C, Feldmann G, Lebrec D, Ogier-Denis E, Bedossa P, Valla D, Durand F: Acute liver cell damage in patients with anorexia nervosa: a possible role of starvation-induced hepatocyte autophagy. Gastroenterology 2008;135:840-848, 848 e841-e843.

5 Narayanan V, Gaudiani JL, Harris RH, Mehler PS: Liver function test abnormalities in anorexia nervosa cause or effect. Int J Eat Disord 2010;43:378-381.

6 Korbonits M, Blaine D, Elia M, Powell-Tuck J: Metabolic and hormonal changes during the refeeding period of prolonged fasting. Eur J Endocrinol 2007;157:157-166.

7 Gunarathne T, McKay R, Pillans L, McKinlay A, Crockett P: Refeeding syndrome in a patient with anorexia nervosa. BMJ 2010;340:c56. 
Vootla and Daniel: Abnormal Liver Function Tests in an Anorexia Nervosa Patient and an Atypical Manifestation of Refeeding Syndrome

8 Sakurai-Chin C, Ito N, Taguchi M, Miyakawa M, Takeshita A, Takeuchi Y: Hypoglycemic coma in a patient with anorexia nervosa coincident with acute exacerbation of liver injury induced by oral intake of nutrients. Intern Med 2010;49:1553-1556.

-9 Harris RH, Sasson G, Mehler PS: Elevation of liver function tests in severe anorexia nervosa. Int J Eat Disord 2013;46:369-374.

10 Mehler PS, Winkelman AB, Andersen DM, Gaudiani JL: Nutritional rehabilitation: practical guidelines for refeeding the anorectic patient. J Nutr Metab 2010;2010:pii 625782.

-11 Delzenne NM, Hernaux NA, Taper HS: A new model of acute liver steatosis induced in rats by fasting followed by refeeding a high carbohydrate-fat free diet. Biochemical and morphological analysis. J Hepatol 1997;26:880-885.

12 Klein CJ, Stanek GS, Wiles CE 3rd: Overfeeding macronutrients to critically ill adults: metabolic complications. J Am Diet Assoc 1998;98:795-806.

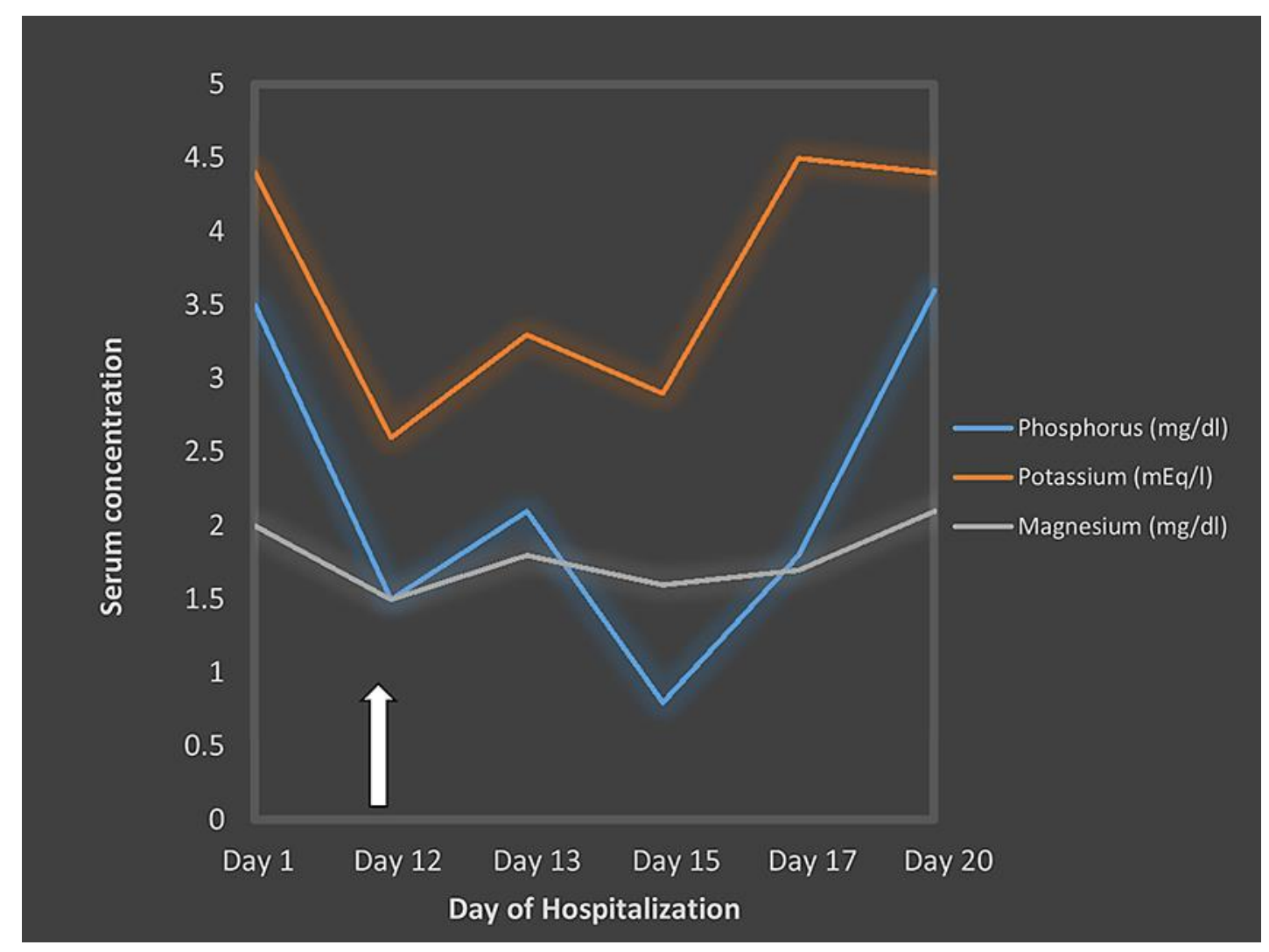

Fig. 1. Variation of electrolytes (potassium, phosphorus and magnesium) during the hospital stay. The arrow depicts the start of tube feeding in the patient (day 8). 


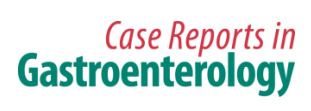

\begin{tabular}{l|l}
\hline Case Rep Gastroenterol 2015;9:261-265 \\
\hline DOI: 10.1159/000437321 & $\begin{array}{l}\text { C 2015 S. Karger AG, Basel } \\
\text { www.karger.com/crg }\end{array}$ \\
\hline
\end{tabular}

Vootla and Daniel: Abnormal Liver Function Tests in an Anorexia Nervosa Patient and an Atypical Manifestation of Refeeding Syndrome

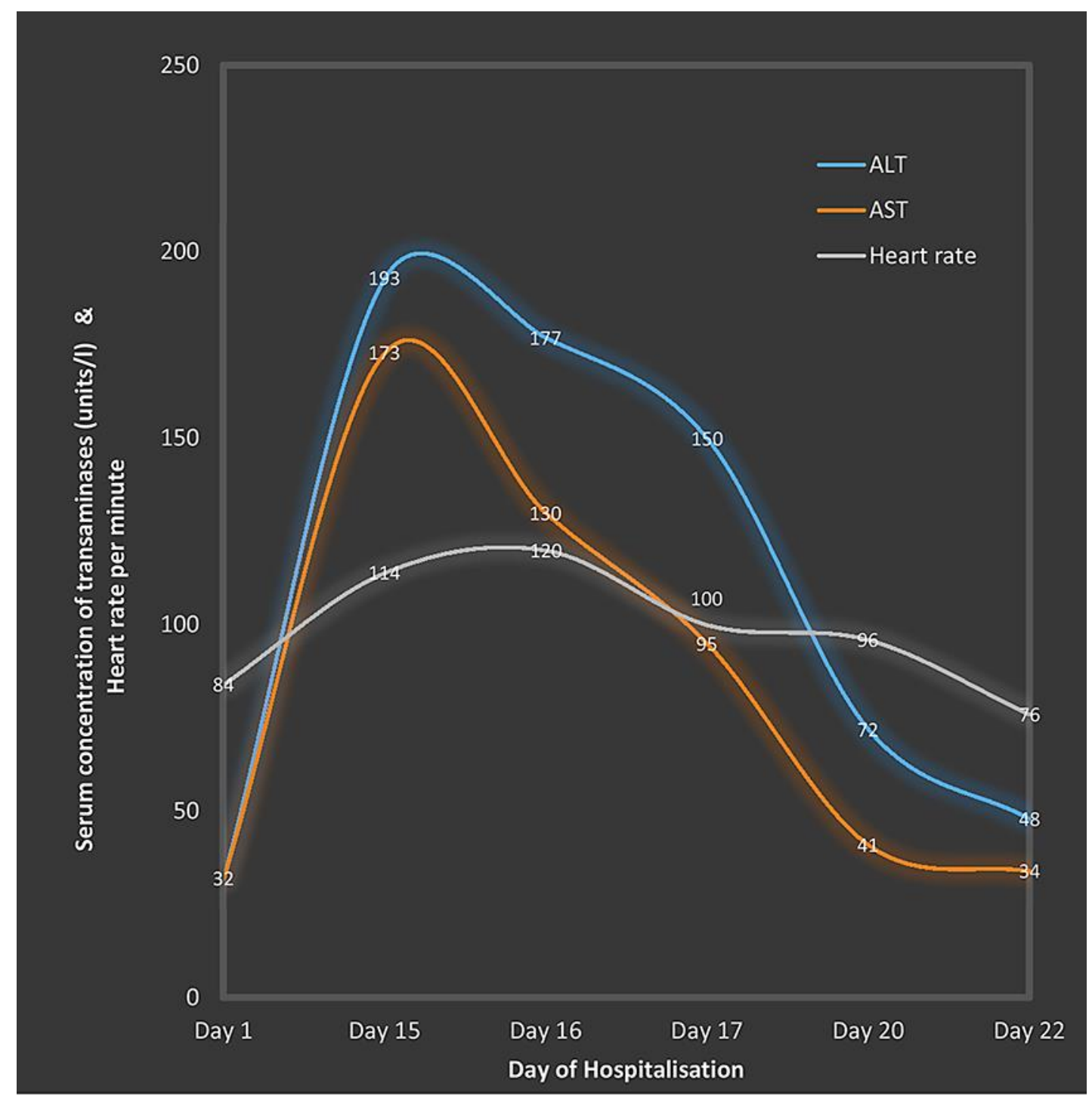

Fig. 2. Trend of transaminases and heart rate during the hospital stay. 